\title{
PREVALÊNCIA E DISTRIBUIÇÃO DE LESÕES DE CÁRIE EM BEBÊS
}

\section{THE PREVALENCE AND THE DISTRIBUITION OF CARIES LESIONS IN BABIES}

\author{
Denise Stadler Wambier'1, Vera Lucia Bosco², Vanessa Cuman ${ }^{3}$, \\ Ornela Smiguel $^{3}$, Tatiana C. Eloy, ${ }^{3}$
}

1 Autor para contato: Universidade Estadual de Ponta Grossa - UEPG, Campus em Uvaranas, Departamento de Odontologia, Ponta Grossa, PR, Brasil;

(42) 224-2907; e-mail: dswambier@zipmail.com.br

2 Universidade Federal de Santa Catarina - UFSC, Departamento de Estomatologia Campus Universitário, Trindade, Florianópolis, SC, Brasil.

3 Universidade Estadual de Ponta Grossa, Campus em Uvaranas, Departamento de Odontologia, Ponta Grossa, PR, Brasil.

Recebido para publicação em 04/05/2004

Aceito para publicação em 15/06/2004

\section{RESUMO}

O objetivo do presente estudo foi descrever a prevalência e a distribuição de lesões de cárie em bebês que frequentavam as creches de Ponta Grossa. Foram examinadas 111 crianças de 6 meses à 3 anos. Foi observada uma prevalência de $21,6 \%$ de crianças com lesões brancas, $18 \%$ de lesões brancas e cavitadas e $7,2 \%$ de lesões cavitadas. A superfície vestibular foi a mais afetada e 3,6\% dessas crianças necessitavam de tratamento odontológico complexo. A alta prevalência de lesões ativas de cárie indica que existe carência de programas educativos/preventivos voltados para essa comunidade.

Palavras-chave: prevalência, cárie, crianças

\begin{abstract}
The aim of the present study was to describe the prevalence and the distribuition of caries lesions in babies that had been attending the Ponta Grossa' nursery. There were examined 111 children from 6 months to 3 years old. The results showed that the prevalence of children with white spots was $21.6 \%$, white spots and decay lesions were $18 \%$ and decay lesions were $7.2 \%$. The vestibular surface was the most affecteded and $3.6 \%$ of these children needed complex odontologic treatment.The high prevalence of active
\end{abstract}


caries lesions showed that there isn't adequate educative care for the preventive programs in this community.

Key words: prevalence, caries, children

\section{Introdução}

Os resultados de estudos regionais que incluíram crianças com menos de três anos de idade demonstraram que a doença cárie está entre as mais prevalentes (Böneckeret al. 2000; Wambier; Deliga, 2000; Moreira et al.2001). Os dados relativos aos cuidados odontológicos em instituições como creches e berçários, e as condições de saúde bucal das crianças matriculadas são escassos. Em geral, não existem nessas instituições, projetos de atenção odontológica, ao contrário do verificado em escolas públicas, onde programas preventivos em saúde já estão incorporados ao sistema.

Os hábitos alimentares inadequados são os principais responsáveis pela ocorrência da doença cárie nos primeiros anos de vida e na maior parte das vezes, os pais não são informados sobre os cuidados essenciais para a manutenção da saúde bucal de seus filhos. Crianças de baixo poder aquisitivo e que permanecem o dia todo nas creches são atendidas por número reduzido de funcionárias que conseguem suprir somente suas necessidades básicas de higiene e alimentação. As crianças na faixa etária do pré-escolar costumam realizar sua higiene bucal, porém esta conduta não faz parte da rotina dos bebês, os quais são completamente dependentes dos adultos. E em casa, as mães com pouco conhecimento e já esgotadas após um dia de trabalho, provavelmente, não se dedicam a esse procedimento que é essencial para a manutenção da integridade dentária e periodontal. Em 1992, o levantamento epidemiológico realizado nas creches da cidade de Ponta Grossa, mostrou que $40 \%$ dos bebês examinados apresentavam lesões de cárie. Na faixa etária de 6 a 18 meses o percentual era de 3\%, passando para 20\% dos 31 aos 36 meses (Wambier; Deliga, 1995). Decorridos oito anos, em outro levantamento epidemiológico, o percentual total de cárie foi de 31\% (Moreira et al. 2001).
O exame de bebês de diversas classes sociais, residentes no estado do Rio de Janeiro, mostrou percentuais de lesões de cárie de 1,56\%; 13,45\% e $35 \%$ nas faixas etárias de 6 a 12 meses, 13 a 24 meses e 25 a 36 meses, respectivamente. A prevalência da doença foi de $16,67 \%$ na faixa etária estudada. Os responsáveis costumavam provar o alimento antes de fornecer para a criança (57\%), desconheciam a forma correta de fazer a higiene bucal $(34,75 \%)$ ou realizavam esse procedimento ocasionalmente (25,10\%). E ainda, 37,42\% dos bebês consumiam alta quantidade de açúcar e 47,12\% eram alimentados durante o sono (Medeiros et al., 1998).

Rosenblatt e Zarzar (2002) em estudo com crianças pernambucanas, na faixa etária de 12 a 36 meses, verificaram que $28,46 \%$ delas apresentavam lesões de cárie. Salientaram que os valores obtidos foram semelhantes aos de outras cidades brasileiras, porém muito elevados quando comparados aos da população mundial.

Pesquisa realizada nas Filipinas mostrou alta prevalência de cárie (59\% aos dois anos e $85 \%$ aos três). Os dentes dessas crianças eram escovados sem assistência materna e esta prática era iniciada, em média, aos dois anos de idade (Cariño et al. 2003).

Nas classes sociais de baixo poder aquisitivo, observa-se maior prevalência de cárie e maior freqüência de preparo de mamadeiras com açúcar (Grindefjord, 1993). O leite é o alimento básico de bebês, mas quando ele é oferecido antes de dormir ou durante à noite, com a diminuição do fluxo salivar e baixa do pH bucal, a ação cariogênica é favorecida (Medeiros, 1993). Esse hábito aliado à higiene bucal deficiente, torna-se um fator de alto risco para o desenvolvimento da doença cárie. Em população de baixo poder aquisitivo, por meio de questionários, verificou-se que $88 \%$ das crianças de 25 a 40 meses utilizavam mamadeira, sendo que entre elas 53\% mamavam para dormir e 35\% dormiam mamando 
(Wambier et al. 2002).

Frisso et al. (1998) trabalhando com os hábitos alimentares e prevalência de cárie em 60 crianças de 6 a 36 meses, não encontraram associação significante entre aleitamento natural e artificial e a presença de cárie. Atribuíram este fato à pequena amostra avaliada. Houve correlação estatisticamente significante entre a preferência alimentar das crianças por doces e a prevalência de cárie. Nas crianças que higienizavam os dentes, a presença da doença cárie foi de $20,5 \%$ e naquelas que não faziam limpeza bucal foi de 38\%, demonstrando uma relação estatisticamente significaste entre ausência de higiene e presença da doença. Lesões de carie estavam presentes em 35\% das crianças (36\% utilizavam leite bovino com açúcar, 36,7\% leite formulado com açúcar, 56,7\% farináceos e 40\% achocolatados).

Cerqueira et al.(1999) analisaram a dieta consumida por bebês, relacionando-a com cárie dentária. Notaram que as crianças ingeriam uma dieta de alta cariogenicidade e que o aleitamento com mamadeiras foi a forma predominante de ingestão do leite, sendo que seu consumo principal era feito na hora da criança dormir.

Os hábitos de higiene bucal de crianças de 0 a 36 meses de idade (Vila Velha/ES) foram avaliados, sendo observado que 53,7\% possuíam o hábito de escovar os dentes diariamente; $48,10 \%$ utilizavam escova e creme dental; $62,5 \%$ dos entrevistados não haviam recebido qualquer orientação sobre cuidados de higiene bucal; 45\% das crianças apresentaram alto índice de placa, sendo que 4\% apresentaram a doença cárie e somente $6,9 \%$ já haviam freqüentado o dentista (Aguiar et al. 1999).

Paula e Dadalto (2000) encontraram 12,9\% de lesões de cárie em bebês de 0 a 36 meses, residentes no bairro Novo Horizonte, município de Serra/ES. O número de dentes cariados nas crianças de 31 a 36 meses que eram amamentadas durante a noite por mais de dezoito meses, foi maior do que em crianças que pararam de mamar até este período. Não foram observadas evidências de que a presença ou ausência de higiene tenha influenciado na prevalência da doença. Os autores esclareceram que os dados foram obtidos de questionários, não sendo portanto possível afirmar que a higiene bucal tenha sido verdadeiramente realizada.
Wyne et al. (2001) examinaram crianças sauditas com dentição decídua para verificar a presença de cárie de mamadeira utilizando como critério a presença de pelo menos dois dentes com lesões de cárie, na superfície vestibular de incisivos superiores. Os resultados mostraram a ocorrência desse padrão de cárie em 27,3\% das crianças examinadas, sendo que os incisivos centrais superiores foram os dentes mais afetados. No estudo de Wambier e Deliga (2000), 17\% dos bebês apresentaram lesões brancas e 14\% cárie de mamadeira e os incisivos superiores também foram os dentes mais afetados.

Fraiz e Walter (2001) concluiram que o padrão dietético foi o principal responsável pelo desenvolvimento de lesões de carie na amostra de seu estudo e que a presença de placa bacteriana visível na superfície vestibular dos incisivos superiores deve ser considerada um importante sinal clínico relacionado a padrões inadequados de higiene bucal e dieta.

Kuhn (2002) observou redução de hábitos inadequados e menor percentual de lesões de cárie $(9,83 \%)$ no grupo de bebês que participou de um programa educativo-preventivo. No grupo controle examinado ao final do estudo, o percentual de lesões de cárie foi maior (38,68\%). Concluiu que ações educativas em programas de promoção da saúde bucal, aliadas ao reforço constante, desenvolvem habilidade materna para o auto cuidado e estimulam hábitos saudáveis.

Freqüentemente a cárie dental em bebês aparece primeiro nos incisivos superiores, onde os líquidos ingeridos da mamadeira permanecem fora do alcance do fluxo salivar (Denbesten; Berkowitz, 2003). Esta cárie tem sido chamada de "cárie de estabelecimento precoce” (Davies, 1998), a qual afeta diferentes classes sociais, mas, principalmente, as de baixo nível sócio-econômico. Realmente, os situados nos estratos de mais alta renda possuem menos cáries que os situados na base da pirâmide social e econômica, desmentindo a afirmativa dos anos oitenta, de que a cárie era uma doença “democrática” (Gomes-Pinto, 2003).

Alveset al.(2001) constataram alto percentual de lesões de cárie em bebês de baixo nível sócioeconômico-cultural, com relato de renda familiar de 
até dois salários mínimos (57\%) e escolaridade baixa, pois $98 \%$ dos responsáveis não haviam completado o segundo grau. Concluíram que o fator sócioeconômico é limitante, tornando estas comunidades de baixa renda dependentes do serviço público.

Um novo termo ou fenômeno chamado de "polarização" tem sido usado para definir a concentração da doença e necessidades de tratamento em pequeno número de indivíduos. Weyne (2003) comentou que essas pessoas pertencem a grupos minoritários socialmente desprotegidos e que apresentam especial vulnerabilidade às doenças, por serem mais suscetíveis ou por estarem mais expostos a fatores de risco.

A identificação de crianças com alto risco ou necessidades acumuladas de tratamento, permite alertar as autoridades para cuidados adequados voltados a essas comunidades. Assim, este estudo objetivou verificar a prevalência e a distribuição da doença cárie em bebês de creches da cidade de Ponta Grossa.

\section{Casuística, materiais e métodos}

Realizou-se um estudo observacional, epidemiológico e transversal em dez creches municipais da cidade de Ponta Grossa/PR, incluindo 111 crianças de 6 meses à 3 anos. $\mathrm{O}$ exame foi realizado somente após obtenção de autorização dos responsáveis e aprovação do projeto de pesquisa pelo Comitê de Ética em Pesquisa da Universidade Estadual de Ponta Grossa (UEPG).

Sob luz natural, no local mais claro do estabelecimento, os bebês foram examinados no colo de duas acadêmicas, na posição “joelho-joelho”. A equipe foi composta por três estudantes, previamente calibradas, sendo uma examinadora e duas auxiliares, as quais empregaram as barreiras de proteção preconizadas (luvas, máscaras). Gazes umedecidas em água destilada foram utilizadas na higiene das superfícies dentárias. Em seguida, os tecidos moles eram afastados com abaixadores de língua, os dentes secos com gaze e as superfícies dentárias examinadas. As lesões de cárie presentes foram registradas em fichas clínicas utilizando-se o índice ceo-s (Gruebbel, 1944 modificado), seguindose estes critérios: lesões brancas foram anotadas com caneta verde, lesões cavitadas, com caneta vermelha e superfícies restauradas foram registradas com caneta preta. Dentes com extensa destruição coronária, indicados para exodontia, receberam dois traços. Essa forma de anotação objetivou facilitar a análise dos dados. Quando necessário, utilizou-se palito para remover algum resíduo de alimento aderido à superfície dentária. Empregou-se somente exame visual e não radiográfico, portanto pequenas lesões interproximais (se presentes) não puderam ser visualizadas.

De acordo com a localização da lesão, utilizou-se a classificação: cárie simples, de mamadeira ou negligenciada. Lesões envolvendo uma única superfície (oclusais e proximais) foram consideradas como simples. A presença de lesões cariosas na superfície vestibular e lingual dos incisivos superiores foram sugestivas de cárie de mamadeira ou similar (chupeta com açúcar, amamentação natural). A classificação de cárie negligenciada, incluiu várias lesões com extenso envolvimento coronário (múltiplas superfícies).

A necessidade de tratamento odontológico foi avaliada e classificada em quatro categorias: tratamento educativo/preventivo, tratamento simples, de média complexidade e complexo. O tratamento educativo/preventivo foi indicado para todas as crianças. O tratamento simples, requeria procedimentos não invasivos (terapia com produtos fluoretados - lesões brancas) ou no máximo restaurações de 3 lesões cariosas (pequenas) em superfícies unitárias. O tratamento de média complexidade, envolvia a necessidade de restaurações de 4 e 5 cavidades. No tratamento complexo, mais de 5 cavidades deveriam ser restauradas, incluindo-se aqui a cárie negligenciada. A figura 1 mostra o modelo da ficha clínica utilizada. 
Nome:

idade:

Data nasc:

sexo: (M)

Creche:

Nome do resp:

End:

Examinador:

Data do exame:

$\mathrm{n}^{\circ}$ dentes

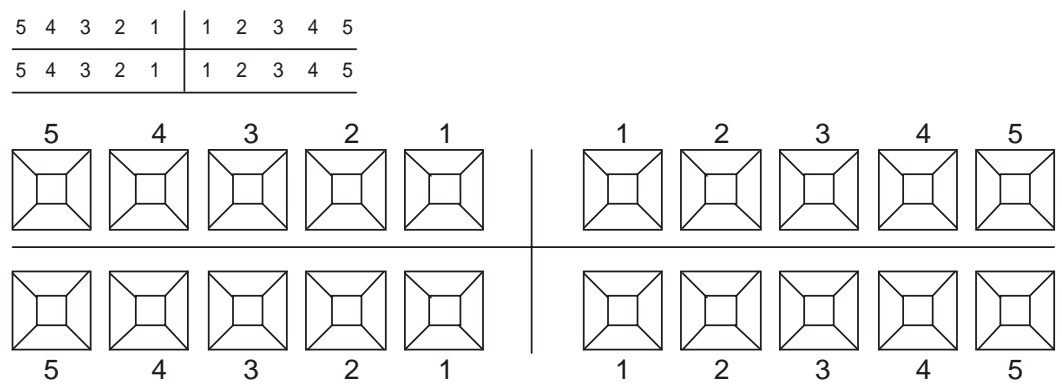

Recebeu tratamento (S) (N) atividade de cárie (S) (N)

simples ( ) mamadeira ( ) negligenciada ( )

Necessidade de tratamento: simples ( ) médio ( ) complexo ( )

Figura 1 - Modelo da ficha clínica

\section{Resultados}

Os resultados desse estudo são mostrados nas tabelas 1 , 2 e 3.

Cento e onze crianças foram examinadas e cinqüenta e duas apresentaram lesões de carie, sendo que 24 possuíam somente lesões não cavitadas (brancas) e 28 apresentavam lesões cavitadas (tabela 1). Verifica-se na tabela 2 que a superfície vestibular foi a mais afetada pelas lesões de carie (115), seguida

Tabela 1- Distribuição das crianças de acordo com o tipo de lesão de cárie apresentado.

\begin{tabular}{l|ll}
\hline Crianças & $\mathbf{n}^{\mathbf{0}}$ & $\mathbf{\%}$ \\
\hline Sem lesões de cárie & 59 & $(53,2 \%)$ \\
Lesões brancas & 24 & $(21,6 \%)$ \\
Lesões brancas e cavitadas & 20 & $(18 \%)$ \\
Lesões cavitadas & 8 & $(7,2 \%)$ \\
\hline Total & 111 & $(100 \%)$ \\
\hline
\end{tabular}

das faces oclusal (81) e lingual (40), respectivamente. Nota-se na tabela 3 que a maior parte das crianças examinadas necessitavam de tratamento simples (42), pois aqui incluíam-se as lesões brancas indicadas para terapia com flúor (25 crianças) e no máximo três lesões cavitadas (17 crianças). Todas as crianças examinadas (111) deveriam ser incluídas em programas educativos e preventivos, visando a manutenção da saúde bucal.

Tabela 2 - Distribuição percentual das lesões de cárie de acordo com as superfícies envolvidas

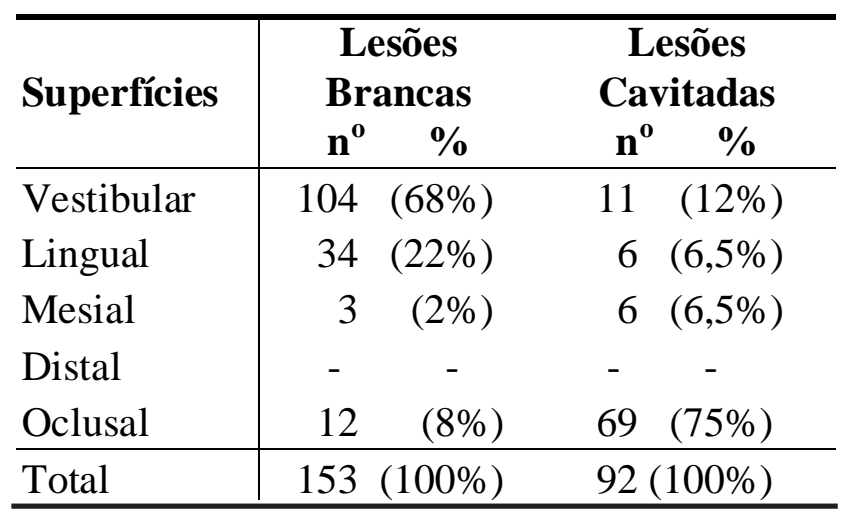


Tabela 3 - Distribuição das crianças segundo a necessidade de tratamento.

\begin{tabular}{l|rc}
\hline Tratamento & $\mathbf{n}^{\mathbf{0}}$ & $\mathbf{\%}$ \\
\hline Educativo/Preventivo & 111 & $(100 \%)$ \\
Simples & 42 & $(37,8 \%)$ \\
Média-complexidade & 6 & $(5,4 \%)$ \\
Complexo & 4 & $(3,6 \%)$ \\
\hline
\end{tabular}

\section{Discussão}

Considerando o pequeno número de crianças incluídas no estudo (111) e em uma faixa etária etária tão jovem, podemos avaliar os resultados como preocupantes. Quase a metade das examinadas apresentavam lesões de cárie (46,8\%), sendo que $25 \%$ delas já apresentavam lesões cavitadas. A presença de lesões brancas, detectadas em $21 \%$ das crianças, é indicativo de atividade de cárie e esta situação predispõe ao desenvolvimento de mais lesões e agravamento das já existentes. O risco de desenvolvimento de doenças bucais se modifica nas diferentes faixas etárias. Assim, a anatomia da superfície oclusal, com sulcos retentivos ao dificultar o acesso da escova, torna-a susceptível ao desenvolvimento de lesões de cárie. Com a erupção do primeiro molar permanente por volta dos seis anos de idade, procura-se dar maior atenção a essa superfície, normalmente a de maior risco à doença. A partir dos doze anos, com todos os dentes permanentes presentes, enfatiza-se a necessidade do uso do fio dental para preservar a integridade das superfícies interproximais. Nas superfícies lisas, não retentivas, a simples desorganização do biofilme dental determinada pela ação mastigatória e "breve" higiene bucal (realizada de forma não tão meticulosa), seriam o suficiente para dificultar a colonização bacteriana. Acrescenta-se ainda o fácil acesso da saliva e de produtos fluoretados, tais como os dentifrícios. Sob esta ótica, na unidade dente, as superfícies vestibular e lingual poderiam ser consideradas as de menor risco cariogênico. Quanto as superfícies oclusais e proximais, seus sítios retentivos, favoreceriam a colonização bacteriana, tornando-as suscetíveis. Contudo na primeira infância, todas as superfícies tornam-se de risco, a medida que hábitos inadequados se fazem presentes. O uso rotineiro da mamadeira impede os efeitos positivos da mastigação, além disto a situação se agrava, quando aos líquidos oferecidos se acrescenta açúcar e a higiene bucal é deficiente.

No presente estudo, as lesões de cárie e sua localização foram o foco de atenção, não sendo avaliada a dieta consumida pelas crianças ou questões relativas à higiene bucal. Porém, sugere-se pela análise dos resultados que a dieta e a higiene são inadequadas no grupo estudado, pois a superfície vestibular foi a mais afetada pelas lesões de cárie presentes (80\%). No estudo de Wyne et al. 2001, a superfície vestibular também foi a mais afetada pela doença cárie.

O estágio inicial da cárie, a lesão branca, foi o mais prevalente nesse estudo. Outros trabalhos também detectaram elevada prevalência dessas manchas ativas nos dentes decíduos (Wambier; Deliga, 1995; Valença et al., 2002).

Os incisivos antecedem os molares e, ao irromperem num meio bucal não controlado são os primeiros dentes sujeitos a desmineralização (Denbesten; Berkowitz, 2003). Se houvesse algum cuidado com a higiene bucal, como já foi dito, a simples desorganização do biofilme dificultaria esse processo. As lesões brancas não tratadas estão sujeitas à cavitação e neste estágio a resolução clínica é mais trabalhosa. Na realidade, a limpeza de superfícies não retentivas dispensa até mesmo o uso da escova. A motivação, orientação e treinamento dos responsáveis na aplicação de procedimentos simples e de baixo custo evitaria a instalação da doença e de suas conseqüências. Pedaços de pano limpo (fraldas) ou algodão umedecidos em água poderiam ser esfregados nos dentes, fazendo assim a remoção de resíduos de alimentos, fonte de nutrientes para as bactérias, mas parece haver carência de informações essenciais à essa comunidade.

A necessidade de tratamento acumulado, seja ele simples ou complexo, requer profissionais habilitados e materiais apropriados para o atendimento infantil. Em serviços públicos a oferta de tratamento, 
principalmente curativo, é escassa. Foi examinado um pequeno grupo de crianças de baixo poder aquisitivo (dependentes do serviço público, pois permanecem nas creches), sendo verificada uma alta necessidade de tratamento. Embora a amostra não seja, pelo número reduzido de crianças examinadas, representativa dos bebês de baixo poder aquisitivo da cidade de Ponta Grossa, a gravidade do problema poderia ser maior do que o verificado nesse estudo. Frente a oferta restrita de tratamento nos serviços gratuitos (postos de saúde, universidades), podemos concluir que o problema detectado tende a evoluir, salvo nos casos em que os pais procurarem atendimento.

O declínio da doença cárie, tendência observada nos últimos anos, precisa englobar também os grupos de indivíduos com risco identificado. No caso de bebês, as pesquisas comprovaram que entre os fatores determinantes da doença, destacaram-se a mamadeira e a ausência de higiene bucal (Moreira et al. 2001; Fraiz; Walter, 2001; Kuhn, 2002). O controle desses fatores negativos, é procedimento essencial nos programas preventivos.

No Brasil, merece destaque o trabalho desenvolvido na Bebê-Clinica da Universidade Estadual de Londrina, onde cuidados preventivos e educativos já beneficiaram muitas crianças, reduzindo e zerando o número de lesões cariosas. Os pais são inicialmente reunidos em grupos para recebimento de informações que visam educar para hábitos saudáveis. Realiza-se o acompanhamento dos bebês para reforço das orientações e aplicação de procedimentos preventivos (Walter et al. 1996). Tomar como exemplo esses programas educativos, colocandoos ao alcance da população que mais necessita, com certeza, seria uma alternativa para minimizar o risco e a gravidade das doenças bucais.

\section{Conclusão}

Os bebês examinados apresentaram alto percentual de lesões ativas de cárie, sendo a superfície vestibular a mais afetada, demonstrando que existe carência de programas educativos/preventivos voltados para essa comunidade.

\section{REFERÊNCIAS}

AGUIAR, A. D.; SANTOS, J. A.; BÖNECKER, M. J. S. Avaliação dos hábitos de higiene bucal de crianças de 0 a 36 meses do município de Vila Velha - ES. Jornal Brasileiro de Odontopediatria \& Odontologia do bebê, v. 2, n. 6, p. 111-118, 1999.

ALVES, F.; MOREIRA, CS; KUMMER,TR, CUMAN,V.; WAMBIER,D. S.; KOZLOWSKI, Jr.,V. Prevalência da doença cárie em bebês de baixo nível sócio-econômicocultural. ENCONTRO ANUAL DE INICIAÇÃO CIENTÍFICA, Ponta Grossa:UEPG, Anais... p.322, 2001.

BONECKER, M. J. S.; MARCENES, W; SHEIHAM, A.;GUEDES-PINTO, AC; WALTER, L. R. F. Redução na prevalência e severidade de cárie dentária em bebês. Jornal Brasileiro de Odontopediatria \& Odontologia do bebê, v.3, p.334-40, 2000.

CARIÑO, K. M.; SHINADA, K.; KAWAGUCHI, Y. Early chilhood caries in northern Philippines. Community Dent Oral Epidemiol. v.31, n.2, p.81-89, 2003.

CERQUEIRA, L. M.; ALVES, M. S. C. F.; BÖNECKER, MJS ;PINHO, ALS. Estudo da prevalência de cárie e da dieta em crianças de 0 a 36 meses na Cidade de Natal-RN. Jornal Brasileiro de Odontopediatria \& Odontologia do bebê, v. 2, n. 2, p. 352-355, 1999.

DAVIES, G. N. Early childhood caries-a synopsis. Community Dent Oral Epidemiol. v.26, n.1, p.106-116, 1998.

DENBESTEN, P.; BERKOWITZ, R. Early childhood caries:na overview with reference to our experience in California. J Calif Dent Assoc, v. 31, n.2, p. 139-43, 2003.

FRAIZ, F. C.; WALTER, L. R. F. Estudo de fatores associados à cárie dental em crianças que recebem atendimento odontológico precoce. Pesquisa Odontológica Brasileira. v.15, n.3, p.201-7, 2001.

FRISSO, G. M., BEZERRA, A. C. B.; TOLEDO, O. A. Correlação entre hábitos alimentares e cárie dentária em crianças de 06 a 36 meses de idade. Jornal Brasileiro de Odontopediatria \& Odontologia do bebê, v. 1, n. 2, p. 1725, 1998.

GOMES PINTO, V. Epidemiologia das doenças bucais no Brasil. In: KRIGER,L (coord.) Promoção de Saúde Bucal. 3. ed. São Paulo: Artes Médicas, 2003, p.25-32.

GRINDEFJORD, M. Caries prevalence in 2.5 year-old children. Caries Res., v.27, p.505-510,1993.

GRUEBBEL, A. O. A measurement of dental caries prevalence and treatament service for deciduous teeth. J Dent Res, v.23, p163, 1944.

KUHN, E. Promoção da saúde bucal em bebês participantes de um programa educativo-preventivo na cidade 
de Ponta Grossa-PR. Dissertação (Mestrado em Saúde Pública). Fundação Oswaldo Cruz. Rio de Janeiro, 2002.

MEDEIROS, U. V. Atenção odontológica para bebês. Rev Assoc Paul Cir Dent.,v.15, n.16, p.18-27, 1993.

MEDEIROS, U. V.; SOUZA, M. I. C.; FONSECA, C. T. Prevalência de cáries em pacientes bebês. Jornal Brasileiro de Odontopediatria \& Odontologia do bebê. v.1, n. 3, p. 23-33,1998.

MOREIRA,C. S., TEIXEIRA, F.; KUMMER,TR, CUMAN,V., WAMBIER,D.S. Perfil de saúde bucal na primeira infância. CONGRESSO NACIONAL DE INICIAÇÃO CIENTÍFICA, 2001, Anais... São Paulo, 2001, v.2, p.376.

PAULA, M. P. G.; DADALTO, E. C. V. Prevalência de cárie em crianças de 0 a 36 meses de idade. Revista ABO Nacional, v. 8, n. 2, p.86-91, 2000.

ROSENBLATT, A.; ZARZAR, P. The prevalence of early childhood caries in 12-to 36-month-old children in Recife, Brazil. ASDC J Dent Child, v. 69, n. 3, p. 319-24, 2002.

VALENÇA, A. M. G.; VASCONCELOS, F. G. G.; CAVALCANTI, A. L.; DUARTE, R. C. Hábitos de higiene, prevalência de manchas brancas e gengivite em crianças de
4 a 12 anos. Pesq Bras Odontoped Clin Integr,v.2, n.1, p.10-15, 2002.

WALTER, L. R. F; FERELLE, A.; ISSAO, M. Odontologia para o bebê. São Paulo: Artes Médicas, 1996, p.209-218.

WAMBIER,D.S.; DELIGA, A.G. Estudo da prevalência da cárie dentária em bebês. PUBLICATIO UEPG - Ciências Biológicas e da Saúde, v.3, n.3, p.7-14, 1995.

WAMBIER, D. S.; DELIGA, A. G. Prevalence of dental caries in babies. J.Dent Res, v.79, 2000. Resumo.

WAMBIER, D. S.; MOREIRA, C. S, TEIXEIRA, F.; KUMMER, TR, CUMAN, V. Correlation among lesions, bacterial plaque, mouth hygiene and the use of the night bottle in babies. J. Dent Res, v.81, p.A345, 2002. Resumo.

WEYNE, S. C. A construção do paradigma de Promoção de Saúde-um desafio para as novas gerações. In: KRIGER,L (coord.). Promoção de Saúde Bucal, 3. ed. São Paulo: Artes Médicas, 2003, p.1-23.

WYNE, A.; DARWISH, S.; ADENUBI, J.; BATTATA S.; KHAN, N. The prevalence an pattern of nursing caries in saudi preschool children. Int J Paediatr Dent. v.11, n.5, p.361-364, 2001. 